\title{
Congenital Aniridia and the Ocular Surface
}

\author{
Robert Ihnatko, Ulla Edén, Per Fagerholm and Neil Lagali
}

Linköping University Post Print

Tweet

N.B.: When citing this work, cite the original article.

Original Publication:

Robert Ihnatko, Ulla Edén, Per Fagerholm and Neil Lagali, Congenital Aniridia and the Ocular Surface, 2016, OCULAR SURFACE, (14), 2, 196-206.

http://dx.doi.org/10.1016/j.jtos.2015.10.003

Copyright: Elsevier

http://www.elsevier.com/

Postprint available at: Linköping University Electronic Press

http://urn.kb.se/resolve?urn=urn:nbn:se:liu:diva-128758 


\title{
SECTION: Clinical Practice, Pedram Hamrah, MD, Editor
}

\section{TITLE: Congenital Aniridia and the Ocular Surface}

AUTHORS: Robert Ihnatko PhD Ulla Eden MD PhD, Per Fagerholm MD PhD, and Neil Lagali, PhD

SHORT TITLE: Congenital Aniridia and the Ocular Surface/Ihnatko, et al

\section{FOOTNOTES}

Accepted for publication October 2015.

From the Department of Clinical and Experimental Medicine, Faculty of Health Sciences, Linköping University, 58183 Linköping, Sweden.

This work was supported by funds from Ögonfonden, The Swedish Research Council, The Country of Östergötland and Kronprinsessan Margaretas Arbetsnämnd.

The authors have no commercial or proprietary interest in any concept or product discussed in this article.

Single-copy reprint requests to Neil Lagali, $\mathrm{PhD}$ (address below).

Corresponding author:

Neil Lagali, PhD, Department of Ophthalmology, Institute for Clinical and Experimental Medicine, Faculty of Health Sciences, Linköping University,

58183 Linköping, Sweden. Tel. +46101034658. Fax +46101033065. Email neil.lagali@liu.se

\begin{abstract}
Aniridia is a congenital pan-ocular disorder caused by haplo-insufficiency of Pax6, a crucial gene for proper development of the eye. Aniridia affects a range of eye structures, including the cornea, iris, anterior chamber angle, lens, and fovea. The ocular surface in particular can be severely affected by a progressive pathology termed aniridiaassociated keratopathy (AAK), markedly contributing to impaired vision. The purpose of this review is to provide an update of the current knowledge of the genetic, clinical, micromorphological, and molecular aspects of AAK. We draw upon material presented in the literature and from our own observations in large aniridia cohorts. We summarize signs and symptoms of AAK, describe current options for management, and discuss the latest research
\end{abstract}


findings that may lead to better diagnosis and new treatment or prevention strategies for this debilitating ocular surface condition.

KEY WORDS aniridia, aniridia- associated keratopathy, congenital aniridia, gene mutations, haplo-insufficiency, iris, Pax6 gene

\section{Introduction}

Congenital aniridia is a disorder caused by a haplo-insufficiency of the Pax6 gene that is often considered the 'master gene' for eye development. ${ }^{1-4}$ Although absence of the iris is the hallmark feature of this disorder, the extent of the iris malformation can vary. ${ }^{5}$ The most common ocular features besides the iris defect are nystagmus, foveal hypoplasia, cataract, glaucoma, and aniridia-associated keratopathy (AAK). ${ }^{1,5,6}$

AAK is one of the most sight-threatening and painful manifestations of congenital aniridia, characterized by a progressive conjunctivalization of the corneal surface with chronic irritation and photophobia. A dysfunctional stem cell niche is thought to give rise to a loss of corneal epithelial phenotype. ${ }^{7}$ In $\mathrm{Pax}^{+/-}$mouse models, there is a developmental delay of the differentiation of the corneal epithelium and a reduction in the number of epithelial cell layers, giving rise to an epithelial fragility. ${ }^{7,8}$ By contrast, the stroma is pathologically thick in mice and in aniridia patients. ${ }^{9-11}$ In addition, in patients the tear film is often unstable and the tear film breakup time (TFBUT) is reduced. ${ }^{12}$ In a combined Swedish-Norwegian cohort with 124 patients, ${ }^{5}$ the mean best spectacle-corrected visual acuity (BSCVA) was 0.2 (20/100), and in a group of 52 children and teenagers under the age of 20, mean BSCVA was less than 0.3 (20/67). Over the age of 40, most patients with AAK are severely visually handicapped. ${ }^{13}$

The focus of our work has been characterizing and understanding the development and progression of AAK after birth. Although several general reviews of aniridia have been published, very few have focused on the ocular surface and AAK. ${ }^{2,8,14}$ Moreover, they were primarily focused on specific aspects of AAK pathophysiology, examining, for example, cellular-level mechanisms leading to AAK based on data from animal models. ${ }^{8}$ Prior reviews are also limited by lack of current knowledge in the field, as they were published over 10 years ago. ${ }^{8,14}$ A more recent review of aniridia published in 2013 focuses, however, on outcomes of surgical interventions available in the treatment of AAK, thus lacking a broader context in the field. ${ }^{2}$ Herein, we provide a review of current knowledge of AAK, integrating the clinical, 
genetic, morphologic, and molecular aspects combined with recent findings reported by our and other research teams as recorded in the PubMed database spanning the years 2003-2015. It is our hope that a deeper understanding of this debilitating condition could lead to its treatment or prevention in the future.

\section{Genetic Considerations}

PAX6 is expressed in each layer of the developing human eye starting at 49 days postfertilization, and there are more than 300 Pax6 gene mutation variants, with penetrance close to $100 \% .{ }^{15}$ Such mutations can be classified into three main groups ${ }^{1,2}$ :

1.Premature termination codons (PTC). These are the most common mutations $(>85 \%)$ in classical aniridia. Mutations that inactivate one copy of the gene typically result in a severe phenotype. No clear correlation, however, has been shown between location of the mutation and the phenotype.

2.C-terminal extension (CTE) mutations. These lead to a run-on sequence predicted to lead to a longer than normal protein. These mutations generally lead to a severe form of aniridia with many complications.

3. Missense mutations. These are mutations that change a single amino acid (substitution) within the protein. These point mutations usually give rise to a milder form of aniridia. They can also cause anterior segment dysgenesis like Peters’ anomaly.

Within each mutation group there can be significant variability in the phenotype. Many other genes interact with PAX6, and some phenotypes may be caused by genetic variation in genes downstream of PAX6. Until now, most clinical studies of aniridia have considered patients with Pax6 gene mutations as a homogeneous group. Clearly, with hundreds of possible mutations, the group exhibits a large heterogeneity, and in the future, clinical assessments and reports would ideally be combined with information on the specific genetic mutation. ${ }^{1,2}$

\section{Knockout Mice Models}

Much of the work on the genetics in aniridia derives from animal studies, often performed on a mouse mutant, Small eye (Sey) mice. ${ }^{7,8,16}$ Human aniridia and heterozygous $\mathrm{Pax}^{+/-}$haplo-insufficiency in the Sey mice are similar with regard to genotype and phenotype. These mice share many of the ocular features of human aniridia and have been 
widely accepted as an animal model. Factors related to the haplo-insufficiency of the Pax6 gene contribute to a limbal stem cell-associated keratopathy in the mouse models. ${ }^{7,8,16,17}$

\section{A. Abnormal Corneal Epithelial Differentiation in Mice}

Even if 60-70 \% of the normal PAX6 protein level is maintained in corneal epithelial cells, serious AAK still results from heterozygous $\mathrm{Pax6}^{+/-}$gene transcription. ${ }^{18}$ PAX6regulated downstream genes are essential for cell differentiation. Expression of cytokeratin 12 (K12) is regarded as a marker for corneal-type epithelial differentiation, and it has been shown that PAX6 expression is essential to the upward regulation of the K12 gene in human corneal epithelial cells. ${ }^{8}$ Deficiency of K12 makes the corneal epithelium fragile and vacuolated.

A study comparing Sey and wild type mice has revealed peripheral lesions in the $\mathrm{Pax}^{+/-}$corneal epithelium. ${ }^{8}$ The barrier between conjunctival epithelium and the corneal epithelium was disrupted. $\mathrm{Pax}^{+/-}$related opacity formations (both in the epithelium and in the stroma) increased in severity with age, which indicates that the opacities arose from both a degenerative process and a failure of corneal differentiation. ${ }^{8}$ The corneal epithelial cells from adult mice have demonstrated abnormal morphology of the nuclei, mitochondria, and cytoskeleton. $^{7,19,20}$

PAX6 also regulates the expression of cell adhesion molecules. Davis et al have shown large gaps between corneal epithelial cells and an unusual appearance of the desmosomes in Sey mice. ${ }^{21}$ These results suggest that desmosomes and the intermediate filaments to which they are attached are abnormal and contribute to the loss of adhesion in the Pax6 ${ }^{+/-}$mutant cornea.

\section{B. Oxidative Stress, Wound Healing, and Corneal Transparency}

In aniridia, corneal epithelial cells are sensitive to oxidative stress, resulting in increased apoptosis and abnormal wound healing. The defective healing is observed both in mice models and clinically, and is related to abnormalities in the cell surface glycoconjugate and deficient and delayed extracellular matrix metabolism. ${ }^{1,7,10,20,22,23}$

The volume of oxidized proteins increases with age in normal corneas but is more extensive in $\mathrm{Pax}^{+/}$. Corneal epithelia, both superficial and basal cells in $\mathrm{Pax}^{+/-}$mice, have 
demonstrated more severe oxidative modifications. ${ }^{24}$ The accumulation of oxidized products occurs in parallel with the development of stromal opacities. Oxidative stress keeps $\mathrm{Pax}^{+/}$ cells in a chronic wound state, which can trigger nuclear exclusion of $\mathrm{Pax}^{+/-}$that has been implicated in transdifferentiation of corneal epithelium into non-corneal phenotype. ${ }^{25}$ This can also lead to abnormal fibroblast/myofibroblast and myoblast expression, suggesting a new pathway linking reduced $\operatorname{Pax}^{+/-}$dosage to aniridia.

One example of the malfunction of keratocytes/fibroblasts/myofibroblasts is their failure to complete the wound healing response, which can lead to the formation of keloid deposits (Figure 1). ${ }^{26}$ The collagenous extracellular matrix of the corneal stroma can also be disrupted in other ways. In MMP-9 deficiency, there is an accumulation of fibrin and premature infiltration of inflammatory cells into the stroma. ${ }^{27}$ MMP-9 belongs to an enzyme group known as matrix metalloproteinases, which are regulated by PAX6. In combination with accumulation of pathologic material, the normal collagen-matrix relationship is disturbed, leading to impaired corneal transparency. ${ }^{8,10}$

In experiments with $\mathrm{Pax}^{+/}$mice, several insights have been gained into impaired corneal wound healing. ${ }^{16,20}$ One important finding was that increased stromal apoptosis occurred after wounding, and it has been suggested that apoptosis, as well as deficient and delayed extracellular matrix metabolism, aggravated the corneal changes. ${ }^{16}$ A summary of the corneal wound healing and stromal response in AAK is given in Table 1.

\section{Clinical Signs and the Stages of Aniridia-Associated Keratopathy}

It is generally believed that AAK starts in the corneal periphery with conjunctival tissue overriding the limbal barrier and growing onto the peripheral cornea. A fibrovascular pannus forms and is opaque with the presence of blood vessels and inflammatory cells. The pannus eventually grows over the corneal surface, so that the border between the conjunctiva and the corneal epithelium is found in the peripheral or mid-peripheral cornea. In a later stage, this pannus then extends to cover the whole surface and the stroma is affected, which gives rise to a decreasing visual acuity.

The stages of progression of AAK can be classified according to a numeric scale;however, several scales have been suggested and consensus would be advantageous. In Tables 2 and 3 and Figure 2, examples of previously published clinical grading scales for AAK are given. Despite the differing scales, a threshold between effect on the central cornea 
(and thereby visual acuity) and non-vision threatening peripheral pathology should ideally be specified.

\section{The Limbal Stem Cells and the Stem Cell Niche}

The corneal limbal stem cells are located between the palisades of Vogt, tightly attached to the basement membrane. The PAX6 genetic defect influences the regulation of the stem cells, leading to a breakdown of normal function of the limbal barrier and causing conjunctiva to invade the corneal surface. ${ }^{20,31}$ The limbus area acts as a junctional barrier to separate the cornea and conjunctiva, and there is no evidence that conjunctival epithelial cells can transdifferentiate into corneal epithelial cells that express $\mathrm{K} 12 .{ }^{8}$

Several studies have shown that stem cell plasticity and pluripotency is determined by environmental factors. In mouse models of aniridia, cell proliferation is not reduced, but it is dysfunctional due to an alteration in the stem cell niche. ${ }^{7,8}$ The presence of conjunctival epithelial cells in the cornea may not only be due to an invasion of the conjunctiva.

Differentiation of progenitor cells into conjunctival and goblet cells in situ in the cornea may occur in an altered corneal microenvironment. The limbal epithelium has been shown to be intermediate between cornea and conjunctiva. ${ }^{8,20}$ Until recently, however, information about the stem cell niche in aniridia has been limited to the heterozygous $\mathrm{Pax}^{+/-}$mouse models. ${ }^{8}$ The recent advancement of in vivo imaging of the cornea by in vivo confocal microscopy of the cornea (IVCM) has enabled a detailed analysis of the limbal stem cell niche in humans. For example, it has been shown that in cases of burn-induced limbal stem cell deficiency (LSCD), the presence of the limbal palisades of Vogt (POV) after limbal stem cell transplantation indicates success of the graft, while absence of the POV indicates failure. ${ }^{32}$

Moreover, IVCM has shown that loss of the POV correlates with loss of central and limbal basal epithelial cells and an increase in limbal dendritic cells. ${ }^{32}$ The corneal or conjunctival epithelial transition zone and cellular phenotype as revealed by IVCM have also been shown in correlation with the presence or absence of the POV in LSCD. ${ }^{33,34}$ In another series of LSCD patients, IVCM was used to examine the POV and limbal epithelium in early, intermediate, and late clinical stages of LSCD, where one could see that the POV were completely degraded at the early stage. ${ }^{35}$

The above studies examined LSCD as a heterogeneous group, often with only one or two aniridia patients included. We recently found in a Norwegian cohort of 20 patients with 
congenital aniridia that the morphology of the POV strongly correlated with stage of aniridiarelated keratopathy. ${ }^{36}$ This strong structure-function relationship of the POV in aniridia revealed that a progressive morphologic degradation of the POV correlates with the loss of limbal and corneal epithelial phenotype. In grade 0 of keratopathy, POV were present with a normal morphological appearance, but in grade 1 almost half of the eyes had partially degraded POV, while in the remaining eyes the POV were absent. In all higher grades, no POV were present, while dendritic cell density was significantly increased.

IVCM could be a useful tool in the discovery of early degradative changes in the limbal palisades of Vogt that lead to progressive conjunctivalization of the ocular surface. Future studies should focus on longitudinal monitoring of the POV and associated morphology in patients, to clarify the processes of degradation of the limbal stem cell niche and offer potential insights for future treatment. ${ }^{37}$

\section{Corneal Nerves}

It appears that corneal nerves are directly or indirectly involved in the regulation of the corneal epithelial stem cells. It is known that corneal nerves release trophic factors to maintain a healthy corneal epithelium and epithelial turnover including limbal epithelial cell maintenance. ${ }^{38,39}$ Nerve growth factor and its receptor Trk-A have been implicated as potential markers for human corneal epithelial stem cells. ${ }^{38,40}$

In mouse models, heterozygous $\mathrm{Pax}^{+/}$adult mice exhibited decreased epithelial innervation and nerve patterns were disrupted. ${ }^{41}$ In humans, IVCM has been used to quantify subbasal epithelial nerves in LSCD, where a markedly reduced nerve density has likewise been found in a case series without aniridia patients ${ }^{35}$ and in a series including two aniridia patients. $^{34}$

In a Swedish cohort of 16 aniridia subjects where IVCM was used, a wide range of subbasal nerve density was reported, including 3 patients with abnormally high innervation of the central cornea. ${ }^{29}$ Nerve patterns were disrupted, and esthesiometry indicated that corneal touch sensitivity was reduced below normal levels in 5 of 14 patients. It was postulated that an apparent high subbasal nerve density could reflect better visibility of these nerves in vivo, due to thinning of the corneal epithelium in aniridia.

In a more recent report describing in vivo corneal nerves in a larger Norwegian cohort of 20 aniridia patients, both limbal and central corneal subbasal nerves were examined. ${ }^{36} \mathrm{~A}$ 
significant correlation was found between limbal epithelial nerve density and grade of keratopathy, while in contrast to the earlier Swedish cohort (where only early-stage keratopathy was examined), the central subbasal nerve density in this larger cohort correlated with grade of keratopathy. ${ }^{36}$ It is important to note, however, that a reduced presence of corneal subbasal nerves, while linked to the status of the keratopathy, is not specific to aniridia. Indeed, reduced subbasal nerve density has been reported in numerous conditions, such as dry eye disease, diabetes, keratoconus, and after refractive surgery and corneal transplantation (for a review of confocal imaging of corneal nerves in disease, see reference 42).

A decrease in corneal nerves in aniridia was observed as one of multiple pathologic signs in the development of keratopathy with concomitant invasion of inflammatory cells, degradation of limbal POV, opacification of the anterior stroma, and loss of basal epithelial cells. ${ }^{29,36}$ While each of these features in isolation is not necessarily specific to aniridia, their combination appears to mirror the progression of AAK.

\section{Central Corneal Epithelium}

Until now the morphology of the central corneal epithelium in AAK has been poorly understood. Although clinical examination by slit lamp microscopy has been used to grade the progression of keratopathy based on peripheral or central corneal involvement, the slit lamp is limited to macroscopic observation. In our Norwegian aniridia cohort, in vivo confocal microscopic imaging showed microscopic-level morphologic changes in the limbal epithelium. ${ }^{36}$ The central cornea, however, exhibits abnormal morphology in aniridia, even in the earliest stages of keratopathy where the central cornea appears clinically normal and transparent. The results of the morphologic findings of central corneal epithelial status are presented in Figure 3, and have not been previously reported.

In particular, early changes to the epithelial wing and basal cell layers are apparent in stage 0 of AAK and progress through to stage 4. Discrete focal opacities appear in the wing cell layers and increase in size as AAK progresses. Wing cell size also appears to increase, as cell borders become less distinct. In the basal epithelium, inflammatory cells infiltrate and increase in density, with goblet cells and vessels invading in the late stages.

Based on animal models of aniridia ${ }^{8}$ and particularly our clinical findings with in vivo confocal microscopy, ${ }^{28,35}$ we hypothesize that limbal epithelial stem cells are present early in 
congenital aniridia, first functioning abnormally for a period, before becoming completely dysfunctional or disappearing. This corresponds to a chain of events culminating in the loss of the limbal epithelial barrier. In the earliest stages (stage 0-1), the limbal stem cell niche in aniridia may be present and functioning but gives rise to epithelial cells with both cornea-like and conjunctiva-like phenotype. In this early stage, stem cell structures such as the limbal POV may be found, and the limbal barrier may be fully or mostly intact. Despite this, conjunctiva-like epithelial cells are produced at the limbus and migrate to the central cornea to form small, isolated 'islands.' Over time, the limbal stem cells begin to produce steadily more conjunctiva-like epithelial cells, in parallel with breakdown of the Palisade structures (stage 12). This leads to establishment of larger conjunctiva-like islands in the central and peripheral epithelium, and also appears to coincide with dendritic cell infiltration into the central cornea, ${ }^{29,36}$ although the central and paracentral regions still appear transparent on clinical observation. Eventually (stages 2-4), limbal stem cell function ceases entirely and can no longer give rise to new epithelial cells, resulting in total breakdown of the limbal barrier and invasion of peripheral conjunctiva into the cornea.

Although more clinical and experimental evidence is required to investigate this proposed chain of events and its specificity to AAK versus general LSCD, the possibility of at least partially functioning limbal stem cells at an early stage in congenital aniridia is promising. It may provide an opportunity for future therapies to halt the decline of limbal epithelial stem cell function, or possibly even reverse it.

\section{Corneal Thickness}

The corneal thickness in aniridia patients is usually increased. Brandt et $\mathrm{al}^{9}$ and Whitson et $\mathrm{al}^{11}$ have reported an increased central corneal thickness, which highlights the importance of correcting measured values of intraocular pressure for the actual corneal thickness. The corneal thickness can be measured with, for example, ultrasonic pachymetry and anterior segment optical coherence tomography (OCT). Central corneal thickness has been reported to vary from $632 \pm 51 \mu \mathrm{m}\left(17\right.$ patients,$\left.{ }^{9}\right)$ to $692 \pm 75 \mu \mathrm{m}\left(10\right.$ patients, $\left.{ }^{11}\right)$, compared to a control group where the thickness was $548 \pm 21 \mu \mathrm{m} .{ }^{11}$ Likewise, in Swedish and Norwegian cohorts, reported median central corneal thickness was $642 \mu \mathrm{m}$ (11 patients $\left.{ }^{29}\right)$ and $623 \mu \mathrm{m}$ (18 patients $^{36}$ ), respectively. Although the origins of the increased stromal thickness in aniridia are unknown, elevated numbers of stromal keratocytes or collagen overproduction have been postulated as possible causes. ${ }^{11}$ 


\section{The Tear Film}

Tear fluid has an important function in the maintenance of the ocular surface, supplying nutrients, proteins, and wound-healing modulating factors that are essential for healthy conjunctival and corneal epithelium. ${ }^{43-47}$ Disturbances in secretion or composition of tear film lead to dysfunction of tear film that displays a broad spectrum of symptoms with varying degree of severity associated with many eye pathologies. ${ }^{48-50}$ The most common is dry eye disease, which can be caused either by deficient tear production or increased tear evaporation. Methods for clinically assessing tear production and function include the Schirmer test, fluorescein-based assessment of TFBUT, and fluorescein and Rose Bengal staining. ${ }^{51}$

In aniridia, the TFBUT is often reduced, suggesting tear dysfunction in the majority of patients. ${ }^{12,29,52}$ The extent of tear instability and meibomian gland dysfunction often correlate with the severity of ocular surface disease ${ }^{12}$ and are not associated with dry eye syndrome per se. ${ }^{52,53}$ Another important factor is tear film osmolarity, which is one of the principal indicators of tear function and the condition of ocular surface. ${ }^{54,55}$ Increased tear osmolarity is a significant stress factor that activates several stress-signaling pathways resulting in transcription of stress-related genes, such as proinflammatory cytokines TNF- $\alpha$, IL-1, IL-6, or matrix metalloproteinases. ${ }^{46,47}$

So far, the osmolarity of aniridic tears has not been assessed and the composition of tear fluid, as well as the expression levels of the particular tear components in aniridia has been largely unknown. Recent research, ${ }^{53}$ however, revealed different levels of several proteins in aniridic tears when compared with healthy tears. In particular, the levels of $\alpha$-enolase, peroxiredoxin 6, cystatin S, gelsolin, and apolipoprotein A-1 were decreased in the tears of aniridia patients, and these proteins, along with the increased levels of $80 \mathrm{kDa}$ isoform of vascular endothelial growth factor that corresponds to VEGF-C, may be involved in the pathogenesis of AAK. AAK is associated with the ingrowth of blood vessels into the cornea that compromise visual acuity. The increased tear levels of VEGF in aniridic tears suggest a breakdown of the balance between pro- and anti-angiogenic factors leading to pathological hem- and lymphangiogenesis and the manifestation of AAK. Increased oxidative stress present in AAK may lead to a greater extent of apoptosis in the corneal epithelium and abnormal corneal wound healing. ${ }^{16}$ In these processes, peroxiredoxin 6, VEGF, gelsolin, apolipoprotein A-1, and zinc- $\alpha 2$ glycoprotein may play a substantial role. One study found elevated levels of dinucleotides $\mathrm{Ap}_{4} \mathrm{~A}$ and $\mathrm{Ap}_{5} \mathrm{~A}$ in aniridic tears. ${ }^{52}$ The increased levels of 
dinucleotides could be related to LSCD as a compensatory mechanism to stimulate the proliferation and differentiation of these cells that are deficient in aniridic eyes.

The anterior lipid layer of tear film contains a large array of nonpolar and polar lipids secreted by the meibomian gland. ${ }^{56,57}$ The main function of this layer is to retard tear evaporation from the ocular surface. ${ }^{56}$ As mentioned, in aniridic eyes the TFBUT is often short, ${ }^{29,52}$ suggesting disturbances in aniridic tear lipidome and the elevated levels of zinc- $\alpha 2$ glycoprotein, ${ }^{53}$ a protein known to stimulate lipid degradation, may play a substantial role in modifying the qualities of the tear lipid layer in aniridia.

The molecular mechanisms on the ocular surface involved in the pathogenesis of aniridia and AAK are presented in Figure 4.

\section{Treatment of Aniridia-Associated Keratopathy}

Therapeutic management of AAK in aniridia depends on the degree of involvement of the ocular surface. As a general recommendation, treatment should be as minimally invasive as possible to avoid accelerating the progression of AAK. ${ }^{58}$ Moreover, any type of aesthetic surgery to substitute the iris should be avoided.

For patients with well-preserved corneal transparency (stage 0 of AAK), artificial tears without preservatives containing sodium hyaluronate can be used to treat corneal irritation. Hyaluronate-containing artificial tears can effectively improve the ocular surface, as demonstrated in patients with dry eye. ${ }^{59}$

In patients with slight-to-moderate keratopathy, autologous serum eye drops can be used to relieve symptoms from the ocular surface and to improve the surface quality. Serum drop therapy proved superior to conventional therapy with substitute tears, improving the ocular surface and comfort in patients with AAK. ${ }^{60}$ An amniotic membrane transplant (AMT) can considerably improve the environment of the extracellular matrix of the limbal epithelial cells during healing of a corneal wound. ${ }^{61}$ AMT has been utilized following pannus removal in AAK, but has provided only temporary improvement in aniridia patients, ${ }^{62}$ with the keratopathy recurring over time.

More invasive treatment to restore the ocular surface in AAK should be considered only in cases of significant reduction of visual acuity and/or recurrent epithelial defects. ${ }^{58}$ Cultured limbal epithelial allograft (allo-CLET) surgery has been attempted and the clinical outcome 
with 14 eyes of 13 aniridia patients and 4 eyes of 4 patients with Stevens-Johnson syndrome was evaluated using the Clinical Outcome Assessment in Surgical Trials Tool (COASTL). ${ }^{37}$ Postoperative visual acuity was improved in $79 \%$ of eyes at 6 months, $71 \%$ at 12 months, $64 \%$ at 18 months, and 57\% at both 24 and 36 months. The COASTL tool showed that following allo-CLET there was a decrease in LSCD severity and an increase in visual acuity up to 12 months post-treatment, but thereafter LSCD severity and visual acuity progressively deteriorated. The allo-CLET surgery provides improvement in ocular surface stability because it temporarily restores the limbal microenvironent, but despite a good immunosuppressant protocol it does not appear to be a long-term solution. Likewise, stem cell culture using autologous cells, which would avoid the adverse effects of graft vs. host reaction, may nevertheless be ineffective in some patients due to a micro-environmental niche in aniridic eyes incapable of supporting and sustaining stem cells in the long term.

Another possibility for treatment of severe corneal opacity is corneal transplantation involving tissue from either a living relative or a cadaveric donor. Surgery using keratolimbal allografts (KLAL) should be done early, before stromal scarring is apparent. The risk of corneal rejection, where the transplanted tissue is a chimera of donor and recipient cells, can be seen even many years after transplantation. Therefore, the KLAL should always be combined with immunosuppression therapy, such as steroids, T-cell inhibitors, or antimetabolites. KLAL can be followed by a penetrating keratoplasty $(\mathbf{P K})$ if the central cornea is involved, but keratoplasty alone will result in graft failure ${ }^{62}$ and often increase the extent of AAK. ${ }^{14}$ The KLAL treatment, however, in many cases results in rejection and graft failure, ${ }^{63}$ and in such cases the Boston keratoprosthesis can be an alternative. To avoid this complication, the keratoprosthesis may also be considered as a first-line treatment. The outcome of the Boston type I keratoprosthesis is promising, although possible complications are not uncommon. Therefore, the postoperative care is of great importance. ${ }^{64}$

Surgery using the Boston keratoprosthesis is often combined with cataract extraction and placement of tube shunts for glaucoma. The outcome of surgery is beneficial; however, the intraocular pressure rises after the surgery. A study involving 26 aniridic eyes of 19 patients who underwent keratoprosthesis implantation showed that 14 eyes had improved visual acuity to $20 / 200$ or better from a preoperative $20 / 300$ or worse. ${ }^{65}$ The mean follow-up time was 28.7 \pm 13.5 months. Another study that involved 16 eyes of 15 patients with aniridia showed improved visual acuity in all but one patient from 20/300 to 20/200; however, follow-up time 
was short (median of 17 months). ${ }^{66}$ No endophthalmitis occurred during the study, but in one patient corneal melting occurred.

It should be mentioned that all intraocular surgery (including cataract surgery) carries a risk of complications in patients with congenital aniridia, such as postoperative fibrosis. The syndrome is characterized by the development of progressive fibrosis of the anterior chamber and the development of a fibrotic membrane probably arising from the rudimentary iris. A possible mechanism that promotes the formation of fibrotic material may be the proximity or touching of intraocular devices on immature vessels in the rudimentary iris found in aniridia. ${ }^{67}$ The progressive fibrosis can displace the lens with ensuing corneal decompensation. If the ciliary body is included, the prognosis is poor with retinal traction. A treatment option is the Boston type I keratoprosthesis alone or in combination with IOL explantation and removal of the fibrotic membrane. ${ }^{68}$ A recent retrospective study of 110 eyes implanted with the Boston type I keratoprosthesis, however, concluded that aniridia eyes are at especially high risk for postoperative complications and tend to have a shortened retention time of the keratoprosthesis. ${ }^{69}$

In the future, another treatment possibility for the corneal surface afflicted by aniridic keratopathy may be implantation of biosynthetic collagen membranes and biocompatible elastomer nanofibers as an alternative to AMT. ${ }^{70}$ These biomaterials are in the experimental stage and their translation into clinical practice is of great interest.

Regardless of the type of intraocular surgery, there is always a risk for progression of the AAK. Several clinical studies have been carried out to address this issue and assess longterm visual prognosis of corneal and ocular surface surgery in aniridia patients. ${ }^{67,71,72}$ The long-term visual prognosis, however, did not differ as a result of surgery for aniridic keratopathy. A study involving 88 eyes of 45 patients with congenital aniridia revealed that either limbal transplantation (LT) or PK provided very little vision improvement upon long term follow-up (16 to 23 years postoperatively). ${ }^{72}$ A combination of LT with subsequent PK when necessary may be helpful for a period of about 3-5 years as a maximum, after which the disease recurs in the majority of cases. ${ }^{72}$ 
Recently, a promising treatment approach using postnatal manipulation of PAX6 dosage in a mouse model has been reported. ${ }^{73}$ This finding gives hope for the future applicability of gene therapy treatment in early aniridia to reverse major PAX6-related congenital eye defects.

\section{Summary and Conclusions}

Optimal medical management of aniridia and particularly the ocular surface in AAK requires an understanding of the complexity of its pathophysiology, integrating knowledge from molecular, clinical, micro-morphological, and in the future, genetic ${ }^{74}$ studies. Careful consideration of each treatment modality with the understanding of AAK pathophysiology is a prerequisite for finding an optimal treatment with improved outcome while potentially avoiding the need for surgical intervention with detrimental effects on patient quality of life and vision. Recent findings suggest that early-stage aniridic keratopathy is characterized by development of focal opacities in the basal epithelium, a subbasal nerve deficit, and infiltration of the central epithelium by dendritic cells, as well as tear film instability, increased corneal thickness, and degradation of limbal palisade architecture. These findings along with specific proteins over- and under-expressed in aniridic tears may help to elucidate the pathogenesis of aniridic keratopathy and aid in developing novel strategies that may be used for future treatment. Additionally, gene therapy approaches are at a promising early stage and require further translational studies. The need for development of new therapies is of utmost importance because 'traditional' intraocular surgery, including stem cell grafting, keratoplasty, and implantation of keratoprosthetics, has not been successful in the long term and may even worsen the patient's prognosis.

The present literature review demonstrates that AAK is a challenging condition to understand and manage; however, our knowledge of the pathologic mechanisms contributing to the degradation of the ocular surface is increasing. Current conservative and invasive surgical treatment options for AAK are of only limited success in the long term and carry the risk of associated complications. At the same time, new treatment options at the molecular and genetic level are being proposed and could improve the prospects for aniridia patients in the future. Very little research has been conducted into these new treatment alternatives, but it is imperative that these lines of investigation continue to develop in order to provide much-needed tools in the arsenal against the relentless progression of AAK. 


\section{References}

1. Hingorani M, Williamson KA, Moore AT, van Heyningen V. Detailed ophthalmologic evaluation of 43 individuals with PAX6 mutations. Invest Ophthalmol Vis Sci 2009;50:2581-90

2. Lee HJ, Colby KA. A review of the clinical and genetic aspects of aniridia. Semin Ophthalmol 2013;28(5-6):306-12 
3. Churchill A, Booth A. Genetics of aniridia and anterior segment dysgenesis. $\mathrm{Br} J$ Ophthalmol 1996;80:669-73

4. Prosser J, van Heyningen V. PAX6 mutations reviewed. Hum Mutat 1998;11:93-108

5. Edén U, Beijar C, Riise R, Tornqvist K. Aniridia among children and teenagers in Sweden and Norway. Acta Ophthalmol Scan 2008;86:730-4

6. Nelson LB, Spaeth GL, Thaddeus SN, et al. Aniridia. A review. Surv Ophthalmol $1984 ; 28: 621-42$

7. Ramaesh T, Ramaesh K, Collinson M. Developmental and cellular factors underlying corneal epithelial dysgenesis in the $\operatorname{Pax}^{+/-}$mouse model of aniridia. Exp Eye Res 2005;81:224-35

8. Ramaesh K, Ramaesh T, Dutton GN, Dhillon B. Evolving concepts on the pathogenetic mechanisms of aniridia related keratopathy. Int J Biochem Cell Biol $2005 ; 37: 547-57$

9. Brandt JD, Casuso LA, Budenz DL. Markedly increased central corneal thickness: an undiagnosed finding in congenital aniridia. Am J Ophthalmol 2004;137:348-50

10. Ramaesh T, Collinson JM, Ramaesh K, et al. Corneal abnormalities in Pax+/- small eye mice mimic human aniridia-related keratopathy. Invest Ophthalmol Vis Sci 2003;44:1871-8

11. Whitson J, Liang C, Godfrey DG, Petroll W M, et al. Central corneal thickness in patients with congenital aniridia. Eye Contact Lens 2005;31:221-4

12. Jastaneiah S, Al-Rajhi AA. Association of aniridia and dry eyes. Ophthalmology 2005;112:1535-40

13. Eden U, Iggman D, Riise R, Tornqvist K. Epidemiology of aniridia in Sweden and Norway. Acta Ophthalmol Scan 2008;86:727-9

14. Mayer KL, Nordlund ML, Schwartz GS, Holland EJ. Keratopathy in congenital aniridia. Ocular Surf 2003;1:74-9

15. Shaw MW, Falls HF, Neel JV. Congenital aniridia. Am J Hum Genet 1960;389-415 
16. Ramaesh T, Ramaesh K, Leask R, Springbett A, et al. Increased apoptosis and abnormal wound-healing responses in the heterozygous $\operatorname{Pax}^{+/-}$mouse cornea. Invest Ophthalmol Vis Sci 2006;47:1911-7

17. Watt FM, Hogan BL. Out of Eden: Stem cells and their niches. Science 2002;287:1427-30

18. Leiper LJ, Walczysko $\mathrm{P}$, Kucerova $\mathrm{R}$, et al. The roles of calcium signaling and ERK1/2 phosphorylation in a $\operatorname{Pax}^{+/-}$mouse model of epithelial wound-healing delay. BMC Biol 2006;4:27

19. Ton CC, Miwa H, Saunders GF. Small eye (SEY); Cloning and characterization on the murine homolog of the human aniridia gene. Genomics 1992;13:251-6

20. Collinson JM, Chanas SA, Hill RE, West JD. Corneal development, limbal stem cell function and corneal epithelial cell migration in the $\mathrm{Pax}^{+/-}$mouse. Invest Ophthalmol Vis Sci 2004;45:1101-8

21. Davis J, Duncan MK, Robison WG, Piatigorsky J. Requirement for $P a x 6^{+/}$in corneal morphogenesis: a role in adhesion. J Cell Sci 2003;116:2157-67

22. Kokotas H, Petersen MB. Clinical and molecular aspects of aniridia. Clin Genet 2010;77:409-20

23. Hanson IM, Fletcher JM, Jordan T, et al. Mutations at the $\mathrm{Pax}^{+/-}$locus are found in heterogenous anterior segment malformations including Peters' anomaly. Nat Genet 1994;6:168-73

24. Ou J, Walczysko P, Kucerova R, et al. Chronic wound state exacerbated by oxidative stress in $\mathrm{Pax6}^{+/-}$aniridia related keratopathy. J Pathol 2008;215:421-30

25. Pearton DJ, Yang Y, Dhouailly D. Transdifferentiation of corneal epithelium into epidermis occurs by means of multistep signals. Proc Natl Acad Sci USA 2005;102:3714-9

26. Dawson DG: Corneal scars, in Dartt DA, Bex P, D'Amore P, et al (eds): Ocular Periphery and Disorders. San Diego, CA, Academic Press. 2011, pp 256-72 
27. Mohan R, Chintala SK, Jung JC. Matrix metalloproteinase, gelatinase B (MMP-9) coordinates and effects epithelial regeneration. J Biol Chem 2002;277:2065-72

28. Edén U, Riise R, Tornqvist K. Corneal involvement in aniridia. Cornea 2010;29:1096-102

29. Edén U, Fagerholm P, Danyali R, Lagali N. Pathologic epithelial and anterior corneal nerve morphology in early-stage congenital aniridic keratopathy. Ophthalmology 2012;119:1803-10

30. Lopez-Garcia JS, Garcia-Lozano I, Rivas L, Martinez-Garchitorena J. Congenital aniridia keratopathy treatment. Arch Soc Esp. Ophthalmol 2006;81:435-44

31. Secker GA, Daniels JT. Corneal epithelial stem cells: deficiency and regulation. Stem Cell Rev 2008;4:159-6.

32. Hong J, Zheng T, Xu J, et al. Assessment of limbus and central cornea in patients with keratolimbal allograft transplantation using in vivo laser scanning confocal microscopy: an observational study. Graefes Arch Clin Exp Ophthalmol 2011;249:701-.

33. Nubile M, Lanzini M, Miri A, et al. In vivo confocal microscopy in diagnosis of limbal stem cell deficiency. Am J Ophthalmol 2013;155:220-3.

34. Miri A, Alomar T, Nubile M, et al. In vivo confocal microscopic findings in patients with limbal stem cell deficiency. Br J Ophthalmol 2012;96:523-.

35. Deng SX, Sejpal KD, Tang Q, et al. Characterization of limbal stem cell deficiency by in vivo laser scanning confocal microscopy. Arch Ophthalmol 2012;130:440-5

36. Lagali N, Edén U, Utheim TP, et al. In vivo morphology of the limbal palisades of Vogt correlates with progressive stem cell deficiency in aniridia-related keratopathy. Invest Ophthalmol Vis Sci 2013;54:5333-42

37. Shortt AJ, Bunce C, Levis HJ, et al. Three-year outcomes of cultured limbal epithelial allografts in aniridia and Stevens - Johnson syndrome evaluated using the Clinical Outcome Assessment in Surgical Trials Assessment Tool. Stem Cells Transl Med 2014;3:265-75 
38. Qi H, Chuang EY, Yoon KC, et al. Patterned expression of neurotrophic factors and receptors in human limbal and corneal regions. Mol Vis 2007;13:1934-41

39. Garcia-Hirschfeld J, Lopez-Briones LG, Belmonte C. Neurotrophic influences on corneal epithelial cells. Exp Eye Res 1994;59:597-605.

40. Qi H, Li DQ, Bian F, Chuang EY, et al. Expression of glial cell-derived neurotrophic factor and its receptor in the stem-cell-containing human limbal epithelium. Br J Ophthalmol 2008;92:1269-74

41. Leiper LJ, Ou J, Walczysko P, et al. Control of patterns of corneal innervation by Pax6. Invest Ophthalmol Vis Sci 2009;50:1122-8

42. Patel DV, McGhee CNJ. In vivo confocal microscopy of human corneal nerves in health, in ocular and systemic disease, and following corneal surgery: a review. $\mathrm{Br}$ J Ophthalmol 2009;93:853-60

43. Wolff E. The muco-cutaneous junction of the lid-margin and the distribution of the tear fluid. Trans Ophthalmol Soc 1946;66:291-308

44. Davidson HJ, Kuonen VJ. The tear film and ocular mucins. Vet Ophthalmol 2004;7:71-7

45. DelMonte DW, Kim T. Anatomy and physiology of the cornea. J Cataract Refract Surg 2011;37:588-98

46. Igarashi T, Fujimoto C, Suzuki H, et al. Short-time exposure of hyperosmolarity triggers interleukin-6 expression in corneal epithelial cells. Cornea 2014;33:1342-7

47. Li DQ, Chen Z, Song XJ, et al. Stimulation of matrix metalloproteinases by hyperosmolarity via a JNK pathway in human corneal epithelial cells. Invest Ophthalmol Vis Sci 2004;45:4302-11

48. Zhou L, Beuerman RW, Chan CM, et al. Identification of tear fluid biomarkers in dry eye syndrome using iTRAQ quantitative proteomics. J Proteome Res 2009;8:4889-905 
49. Wong TT, Zhou L, Li J, et al. Proteomic profiling of inflammatory signaling molecules in the tears of patients on chronic glaucoma medication. Invest Ophthalmol Vis Sci 2011;52:7385-91

50. Kim HJ, Kim PK, Yoo HS, Kim CW. Comparison of tear proteins between healthy and early diabetic retinopathy patients. Clin Biochem 2012;45:60-7

51. Korb DR. Survey of preferred tests for diagnosis of the tear film and dry eye. Cornea 2000;19:483-6

52. Peral A, Carracedo G, Pintor J. Diadenosine polyphosphates in the tears of aniridia patients. Acta Ophthalmol 2015;93:e337-42.

53. Ihnatko R, Eden U, Lagali N, et al. Analysis of protein composition and protein expression in the tear fluid of patients with congenital aniridia. J Proteomics 2013;94:78-88

54. Lemp MA, Bron AJ, Baudouin C, et al. Tear osmolarity in the diagnosis and management of dry eye disease. Am J Ophthalmol 2011;151:792-8 e1

55. Tomlinson A, Khanal S, Ramaesh K, et al. Tear film osmolarity: determination of a referent for dry eye diagnosis. Invest Ophthalmol Vis Sci 2006;47:4309-15

56. DELETE: DUPLICATE OF 46 Igarashi T, Fujimoto C, Suzuki H, et al. Short time exposure of hyperosmolarity triggers interleukin 6 expression in corneal epitheliat eells. Cornea 2014;33:13427

57. 56. Bron AJ, Tiffany JM, Gouveia SM, et al. Functional aspects of the tear film lipid layer. Exp Eye Res 2004;78:347-60

58. 57. Tiffany JM. The normal tear film. Dev Ophthalmol 2008;41:1-20

59. 58. Seitz B, Käsmann-Kellner B, Viestenz A [Stage-related therapy of congenital aniridia]. Ophthalmologe. 2014;111(12):1164-71. German

60. 59. Aragona P, Papa V, Micali A, et al. Long term treatment with sodium hyaluronate-containing artificial tears reduces ocular surface damage in patients with dry eye. Br J Ophthalmol 2002;86:181-4 
61. 60. Lopez-Garcia JS, Rivas L, Garcia-Lozano I, Murube J. Autologous serum eyedrops in the treatment of aniridic keratopathy. Ophthalmology 2008;115:262-7

62. 61. Kim JS, Kim JC, Na BK, et al. Amniotic membrane patching promotes healing and inhibits proteinase activity on wound healing following acute corneal alkali burn. Exp Eye Res 2000;70:329-37

63. 62. Lopez-Garcia JS, Rivas L, Garcia-Lozano I. [Moderate limbal deficiency in patients with congenital aniridia treated with amniotic membrane transplantation]. Arch Soc Esp Oftalmol 2005;80:517-23. Spanish

64. DELETE: ĐUPLICATE OF 37Shortt AJ, Bunce C, Levis HJ, et al. Three-year outcomes of cultured limbal epithelial allografts in aniridia and Stevens-Johnsen syndrome evaluated using the Clinical Outcome Assessment in Surgical Trials assessment tool. Stem Cells Transl Med 2014;3:265-75

65. 63. Ang AY, Chan CC, Biber JM, Holland EJ. Ocular surface stem cell transplantation rejection: incidence, characteristics, and outcomes. Cornea 2013;32:229-36

66. 64. Holland EJ, Djalilian AR, Schwartz GS. Management of aniridic keratopathy with keratolimbal allograft: a limbal stem cell transplantation technique.

Ophthalmology 2003;110:125-30

67. 65. Hassanaly SI, Talajic JC, Harissi-Dagher M. Outcomes following Boston type 1 keratoprosthesis implantation in aniridia patients at the University of Montreal. Am J Ophthalmol 2014;158:270-6.

68. 66. Akpek EK, Harissi-Dagher M, Petrarca R, et al. Outcomes of Boston keratoprosthesis in aniridia: a retrospective multicenter study. Am J Ophthalmol 2007; $144: 227-31$

69. 67. Tsai JH, Freeman JM, Chan CC, et al. A progressive anterior fibrosis syndrome in patients with postsurgical congenital aniridia. Am J Ophthalmol 2005; 140:1075-9 
70. 68. Bakhtiari P, Chan C, Welder JD, et al. Surgical and visual outcomes of the type I Boston Keratoprosthesis for the management of aniridic fibrosis syndrome in congenital aniridia. Am J Ophthalmol 2012;153:967-71

71. 69. Wang Q, Harissi-Dagher M. Characteristics and management of patients with Boston type 1 keratoprosthesis explantation--the University of Montreal Hospital Center experience. Am J Ophthalmol 2014;158:1297-1304

72. 70. Fuchsluger T, Salehi S, Petsch C, Bachmann B. [New possibilities for ocular surface reconstruction: collagen membranes and biocompatible elastomer nanofibers]. Ophthalmologe 2014;111:1019-26. German

73. 71. Chang JW, Kim JH, Kim SJ, Yu YS. Congenital aniridia: long-term clinical course, visual outcome, and prognostic factors. Korean J Ophthalmol 2014;28:479-8.

74. 72. de la Paz MF, Alvarez de Toledo J, Barraquer RI, Barraquer J. Long-term visual prognosis of corneal and ocular surface surgery in patients with congenital aniridia. Acta Ophthalmol 2008;86:735-40

75. 73. Gregory-Evans CY, Wang X, Wasan KM, et al. Postnatal manipulation of Pax6 dosage reverses congenital tissue malformation defects. J Clin Invest 2014;124:111-6

76. 74. Dubey SK, Mahalaxmi N, Vijayalakshmi P, Sundaresan P. Mutational analysis and genotype-phenotype correlations in southern Indian patients with sporadic and familial aniridia. Mol Vis 2015;21:88-97 
Table 1. Corneal wound healing and stromal responses in healthy and PAX6 deficient eyes. (adapted from ref. [8])

\begin{tabular}{|l|l|l|}
\hline & $\begin{array}{l}\text { Normal eye } \\
\text { (functioning PAX6 gene) }\end{array}$ & $\begin{array}{l}\text { Aniridia } \\
\text { (PAX6 mutation) }\end{array}$ \\
\hline \hline Gene status & Up-regulation of Pax6 & Reduced PAX6 activity \\
\hline Enzymatic activity & Up-regulation of MMP-9 & Deficient MMP-9 activity \\
\hline Extracellular matrix & Normal matrix remodelling & Aberrant matrix remodelling \\
\hline Wound healing & Normal healing response & $\begin{array}{l}\text { Inflammatory cell pre- } \\
\text { infiltration } \\
\text { Overexpression of IL-1 } \\
\text { Corneal neovascularization } \\
\text { Stromal scarring }\end{array}$ \\
\hline
\end{tabular}

Table 2. Classification of aniridia-associated keratopathy (AAK)

\begin{tabular}{|l|l|}
\hline Aniridia-Associated Keratopathy & Stage \\
\hline Clear, fully transparent cornea & 0 \\
\hline Some cloudiness in the periphery/limbus indicating ingrowth of vessels & 1 \\
\hline $\begin{array}{l}\text { Minor opacifications with ingrowth of vessels, not disturbing visual acuity } \\
\text { opacification of the corneal stroma and centripetal ingrowth of vessels, } \\
\text { reduced visual acuity }\end{array}$ & 2 \\
\hline $\begin{array}{l}\text { Opacification of entire cornea } \\
\text { End stage, thick opaque pannus, fully vascularized cornea }\end{array}$ & 3 \\
\hline
\end{tabular}

Adapted from reference 28 . 
Table 3. An alternative classification of aniridia associated keratopathy AAK into three phases (adapted from [30]).

\begin{tabular}{|l|l|l|l|}
\hline & Erosion/ulcer & Vascular pannus & Signs + symptoms \\
\hline $\begin{array}{l}\text { 1. Slight limbal } \\
\text { insufficiency }\end{array}$ & $\begin{array}{l}\text { Max 2 recurring } \\
\text { erosions or ulcers } \\
\text { within 6 months }\end{array}$ & $\begin{array}{l}\text { Not exceeding 1 } \\
\text { mm from the } \\
\text { limbic arch }\end{array}$ & $\begin{array}{l}\text { Small disorders in absorption } \\
\text { of fluorescein, slight epiphora } \\
\text { and photophobia }\end{array}$ \\
$\begin{array}{l}\text { 2. Moderate } \\
\text { insufficiency }\end{array}$ & $\begin{array}{l}\text { More than 3 } \\
\text { recurring erosions } \\
\text { or ulcers within 6 } \\
\text { months }\end{array}$ & $\begin{array}{l}\text { Involves at least } \\
\text { the peripheral half } \\
\text { of the cornea }+/- \\
\text { subepithelial } \\
\text { fibrosis }\end{array}$ & $\begin{array}{l}\text { Permanent instability of the } \\
\text { lacrimal film; constant red } \\
\text { eye, epiphora and } \\
\text { photophobia }\end{array}$ \\
\hline $\begin{array}{l}\text { 3. Severe limbal } \\
\text { insufficiency }\end{array}$ & $\begin{array}{l}\text { Permanent signs } \\
\text { of corneal erosion }\end{array}$ & $\begin{array}{l}\text { Central cornea } \\
\text { involved }\end{array}$ & $\begin{array}{l}\text { Permanent instability of the } \\
\text { lacrimal film; constant red } \\
\text { eye, epiphora, photophobia } \\
\text { and loss of vision }\end{array}$ \\
\hline
\end{tabular}



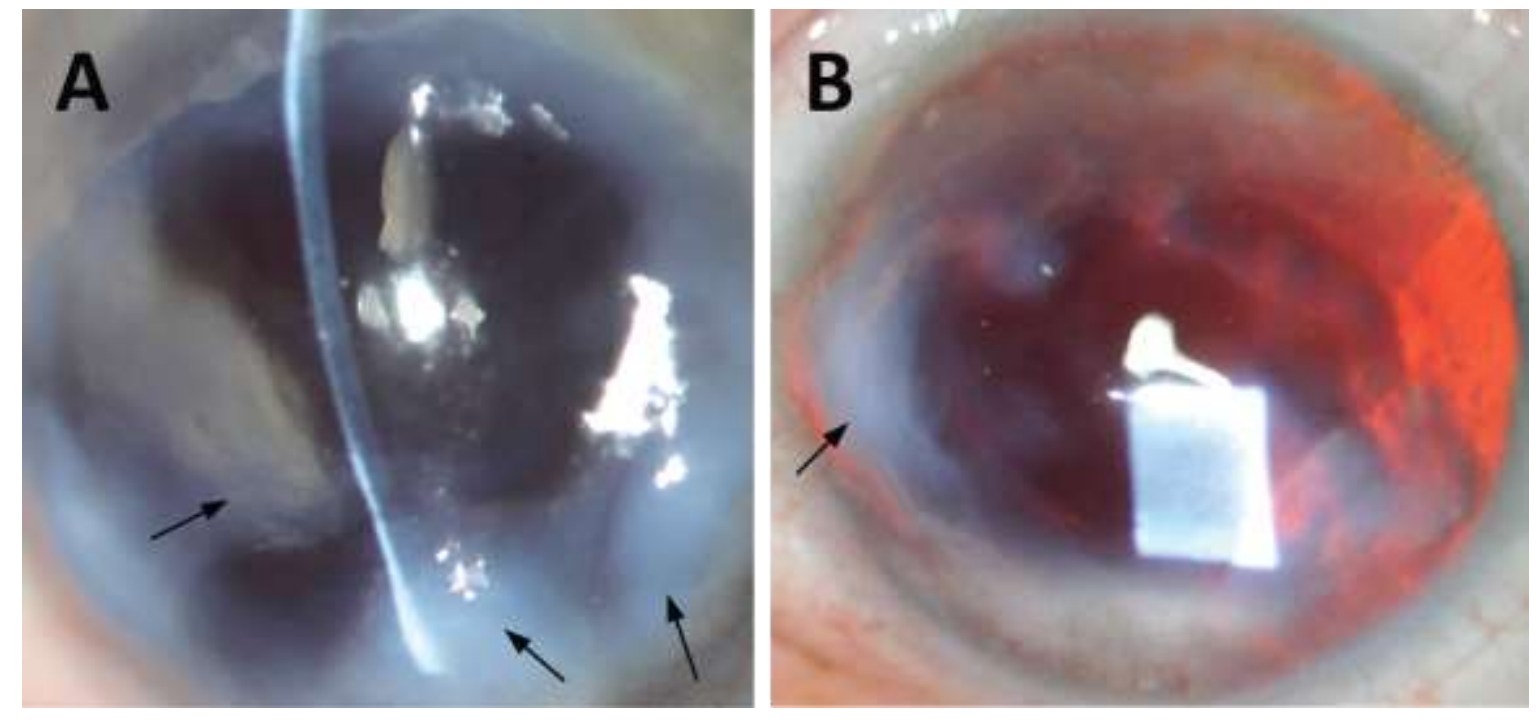

Figure 1. Corneal keloid formations in two aniridia patients. A. Keloids (arrows) appear as coalesced thick, whitish fibrous deposits in the mid-peripheral to peripheral cornea in direct slit illumination. B. A peripheral keloid deposit (arrow) viewed in retroillumination. 


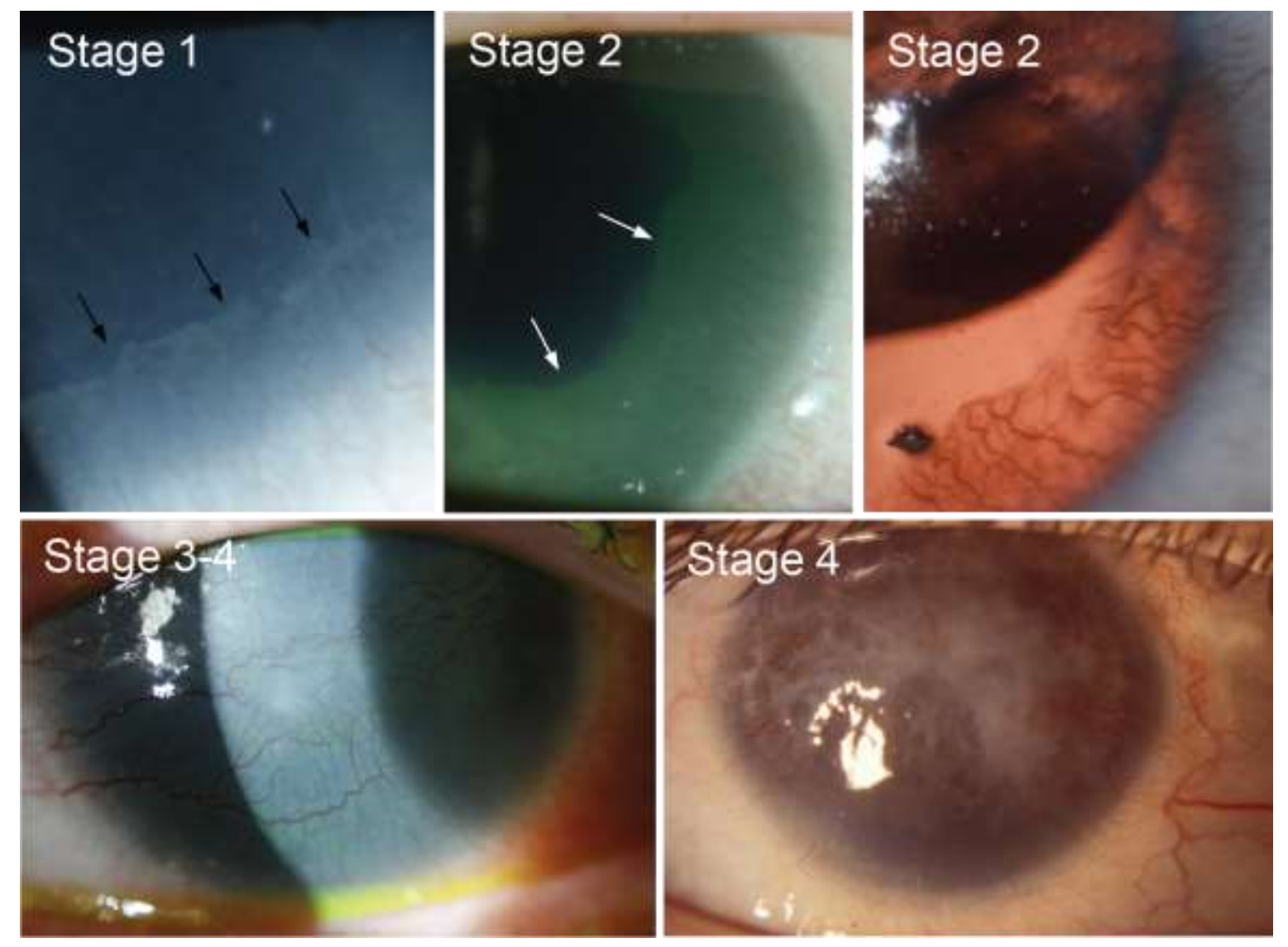

Figure 2. Clinical grading of aniridia stage as described in Table 2. In Stage 1, conjunctival tissue containing vessels extends just over the limbal barrier (black arrows). In Stage 2, conjunctivalization of the corneal surface proceeds, encroaching into the peripheral and midperipheral region (white arrows), while the central cornea remains clear. (reproduced with permission from reference 28). 

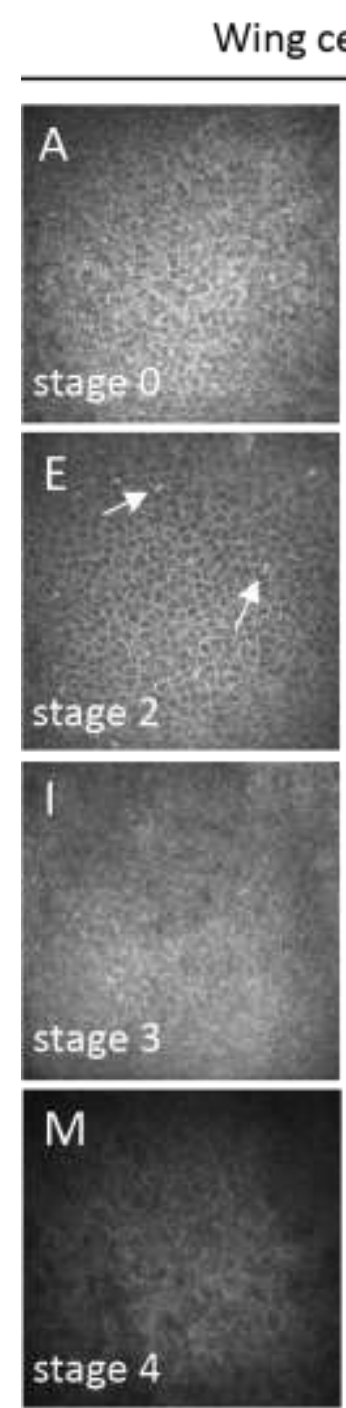
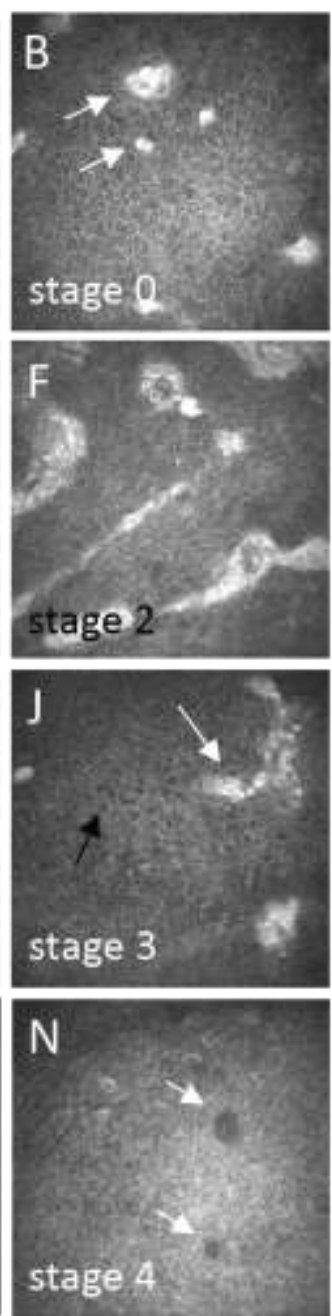

Basal cell layer
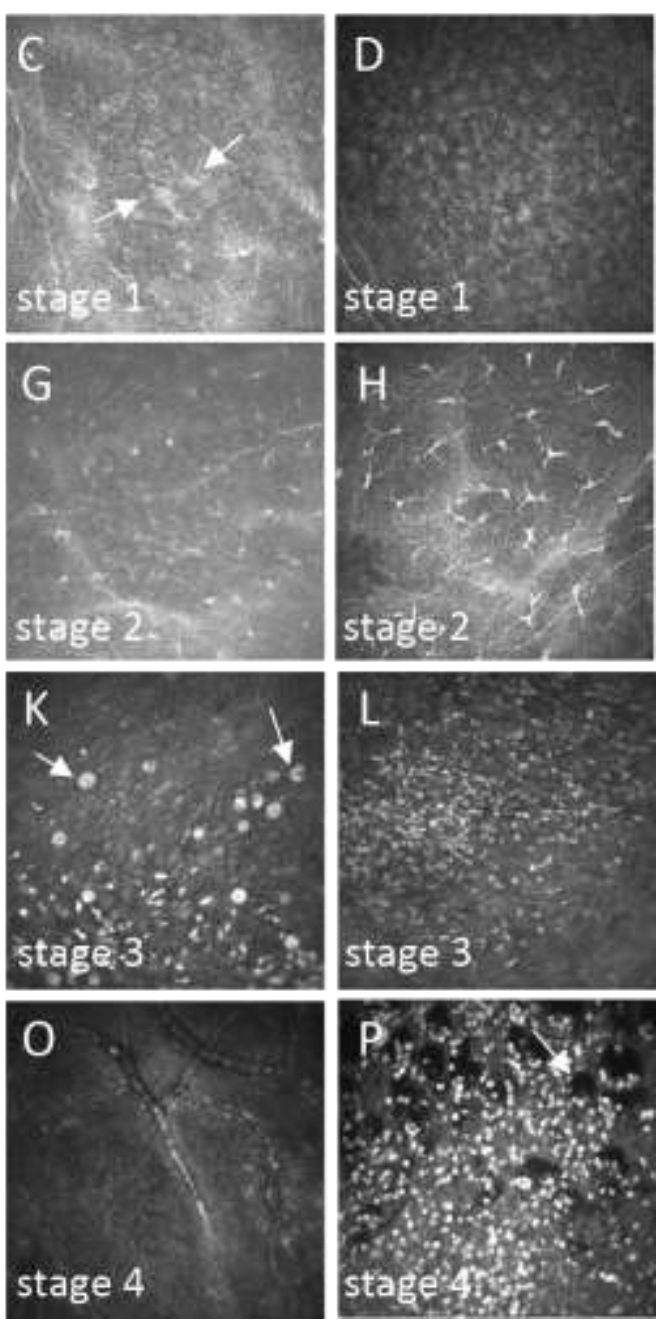

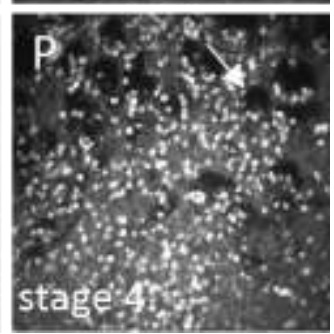

Figure 3. Central corneal epithelial morphology in various stages of AAK. Central corneal involvement becomes clinically apparent only in stages 3 and 4, while microscopically, pathology is evident even in stage 0 . A, B. Wing cell layer may appear normal, but can have discrete opacities (arrows). C, D. Basal cells may exhibit early changes in light scatter (arrows). E. Dendritic cell infiltration (arrows) of wing cell layer in stage 2. F. larger focal opacities. .(G, H. Accumulation of central dendritic cells in different patients with stage 2 AAK. I. Indistinct cell borders and enlarged wing cells. J. Opacities (white arrow) and dark vacuole-like structures (black arrow) in stage 3 AAK. K. Infiltration of goblet cells (arrows). L. Dense infiltration of inflammatory cells. M. Enlarged wing cells in stage 4. N. Dark vacuoles (arrows) amidst conjunctiva-like epithelial cells. O.

Vessels invade the basal epithelium. P. Infiltration of inflammatory cells and large, dark vacuoles (arrow) in the basal epithelium in stage 4 AAK. All images $400 \times 400 \mu \mathrm{m}$. 


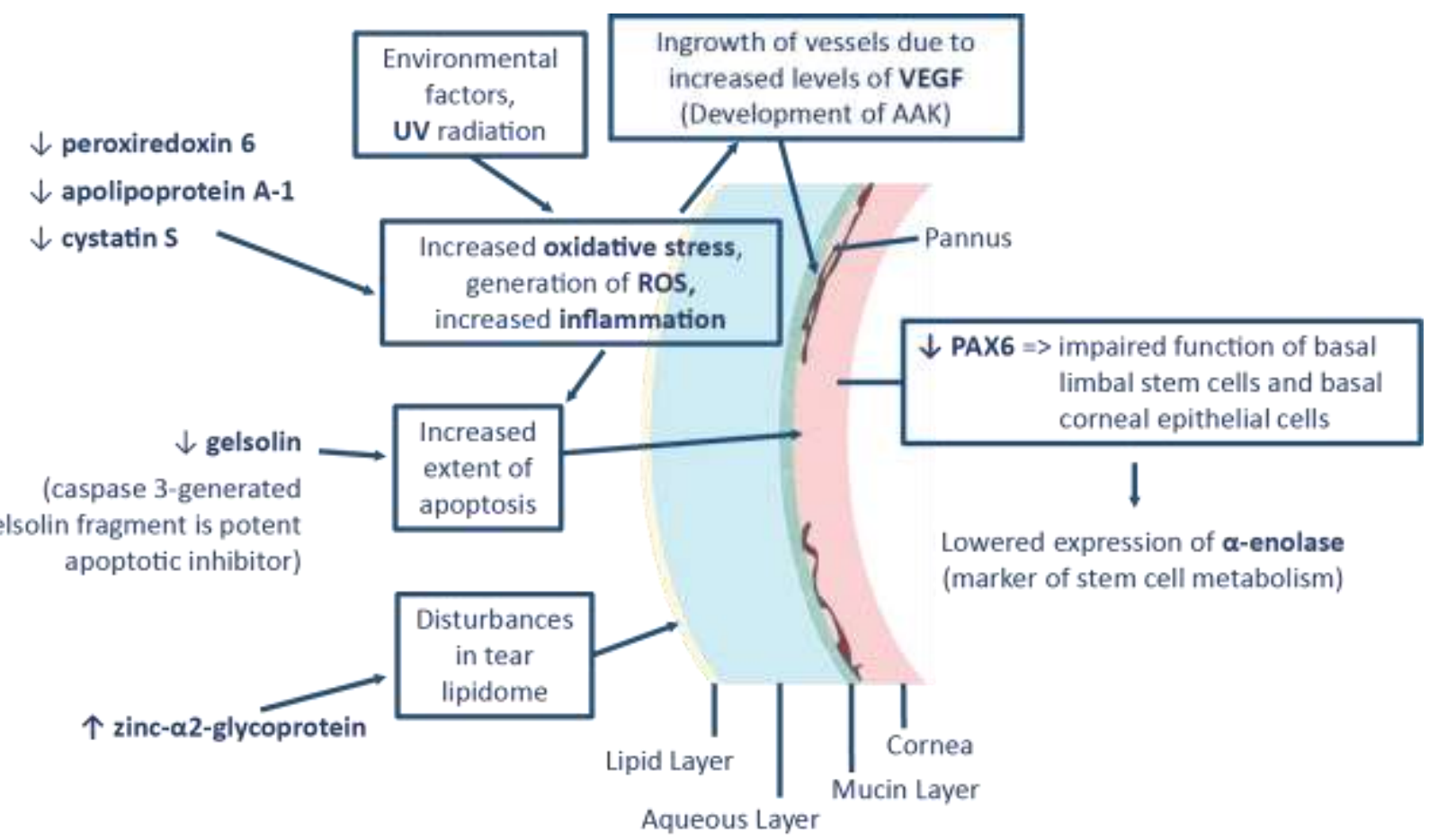

Figure 4. Proposed molecular mechanisms on the ocular surface involved in the pathogenesis of aniridia and AAK, based on a recent study. ${ }^{53}$ 